\title{
Article \\ A Design of a Solar Fermentation System on Chicken Manure by Fuzzy Logic Temperature Control
}

\author{
Jin-Jhu Su ${ }^{1,2}{ }^{,}$Hsi-Chuan Huang ${ }^{3}$, Yi-Ching Chen ${ }^{1, *}$ (D) and Ming-Yao Shih ${ }^{3}$ \\ 1 Department of Environmental Engineering, Da-Yeh University, Changhua 515006, Taiwan; \\ machael1889@hotmail.com \\ 2 School of Horticulture and Landscape Architecture, Fujian Vocational College of Agriculture, \\ Fuzhou 350007, China \\ 3 Department of Automation Engineering, Chengkuo Technology University, Changhua 500020, Taiwan; \\ schwang@cc.ctu.edu.tw (H.-C.H.); smy68688388@gmail.com (M.-Y.S.) \\ * Correspondence: yiching@mail.dyu.edu.tw; Tel.: +886-939-107-419
}

Citation: Su, J.-J.; Huang, H.-C.;

Chen, Y.-C.; Shih, M.-Y. A Design of a Solar Fermentation System on Chicken Manure by Fuzzy Logic Temperature Control. Appl. Sci. 2021, 11, 10703. https://doi.org/10.3390/ app112210703

Academic Editor: Francesca Raganati

Received: 4 October 2021

Accepted: 9 November 2021

Published: 12 November 2021

Publisher's Note: MDPI stays neutral with regard to jurisdictional claims in published maps and institutional affiliations.

Copyright: () 2021 by the authors. Licensee MDPI, Basel, Switzerland. This article is an open access article distributed under the terms and conditions of the Creative Commons Attribution (CC BY) license (https:// creativecommons.org/licenses/by/ $4.0 /)$.

\begin{abstract}
Traditional chicken manure fermentation is mostly natural composting or exposure, which is not only time consuming but also susceptible to weather, resulting in uncontrollable quality and environmental pollution. This research aims to build a smart solar chicken manure fermentation system to control the conditions of chicken manure fermentation effectively, improve quality, and solve the problems of environmental pollution. Hot water produced by solar energy is the heat source for the main system of fermentation, and a backup supplemental heat source by gas heater is applied. The mechanism of drive, agitation, ventilation and drying as well as temperature conditions are controlled by the Arduino's control core. Fuzzy logic is applied to maintain the optimal temperature, so that the system decomposes the bacteria optimally and reduces the consumed time for fermentation. The chicken manure humidity can be decreased from $70 \%$ to $30 \%$, and the effective control system temperature is between 40 and $42{ }^{\circ} \mathrm{C}$, while the $\mathrm{pH}$ value is changed from 8.7 to 7.4 . The sample analysis of the fermentation also shows that there was $13.12 \%$ more organic matter in the chicken manure that added the decomposing bacteria than which did not contain the decomposing bacteria.
\end{abstract}

Keywords: fermentation; solar energy; fuzzy logic; temperature control

\section{Introduction}

Animals' manure contains 70-90\% organic matter, nitrogen, phosphorus and may causes pollutants without proper disposal. For example, each chicken has a daily excreta discharge of $52-81 \mathrm{~g}$ with $50.5 \%$ water content, which contains $25.5 \%$ of organic matter, $1.63 \%$ of nitrogen, and $1.54 \%$ of phosphorus [1]. The manure potentially has a high concentration of pollutants; on the other hand it is also the nutrients required by plants, such as production and utilization of compost in Taiwan by a livestock research institute [2]. It can be seen on the report discussing the development and application of new biological fertilizers in Taiwan [3], and also the report referring the production and use of organic fertilizer [4]. Proper disposal and reuse of the manure could achieve the purpose of compost resource. At present, the treatment methods of livestock manure mainly include solid liquid separation, anaerobic treatment, and aerobic treatment.

The deficiency of the traditional composting method is that it is flipped and stacked for 1 to 3 months, and there are problems such as stinking, sewage, and large stacking space. Therefore, the current composting manufacturing method has become mechanized, and a ventilation system is applied to shorten the fermentation time. Traditional composting methods utilize microorganisms in nature to decompose the unstable organic components in the waste under controlled conditions and convert them into a stable humic acid (HA) component, which is called "compost", such as the research of De Bertoldi et al. [5], Zhou et al. [6], and Xu's thesis [7]. In the process of composting, microorganisms always 
play an important role in the decomposition of organic matter and the stabilization of compost. During the composting process, the carbohydrates contained in the organic matter are rapidly decomposed by microorganisms, and the proliferation of microorganisms is required to absorb nitrogen, phosphorus and other nutrients to combine synthetic microbial constitution (biomass) [8,9]. Different stacked materials are inoculated with appropriate microbial strains to accelerate composting. In addition, maintaining the optimal growth conditions of the microorganisms and allowing the microorganisms to fully move and reproduce can enhance the fermentation and decomposition of the compost material as well. For green energy applying to fermentation, different inventions and techniques aimed at providing solar heat fermentation equipment were designed to treat biowaste, such as a China Patent in 2009 [10] and another China Patent in 2014 [11], or even produce bioethanol [12].

However, in order to maintain a suitable temperature for microbial fermentation, a solar temperature-controlled livestock manure fermentation system was designed in the current study [13]; it aims to effectively control the temperature of the fermentation tank by fuzzy logic algorithm and shorten the fermentation time by using solar heating. Fuzzy Logic Control (FLC) linearly interpolating any value between zero and one differs from traditional controls of zero and one only [14]. Currently, FLC technology is widely used in optimal design of the fuzzy Proportional Integral Derivative (PID) controllers [15], DC-to-DC converter in microcontrollers [16], fuzzy logic controller (FLC) for a Pulse Width Modulation (PWM) boost converter [17], and DC Servo Motor fuzzy control [18]. The present study applied the FLC technology on the solar water heater of the temperature controller to maintain a constant temperature in the tank with the intelligent solar fermentation system for optimal fermentation temperature conditions. Here in this study, the Tsukamoto fuzzy model [19] is used to aggregate the output of each rule and the center-of-gravity method is also used as defuzzification, which can meet the relative simplicity and needs of practical agricultural applications.

Through the fuzzy logic intelligent control, the fermentation barrel temperature could be stably maintained at about $40{ }^{\circ} \mathrm{C}$. After around $50 \mathrm{~h}$, chicken manure formed small particles which were assumed to reach a dry and powdery state. Germination efficiency was determined by culturing seeds with fermented fertilizer of chicken manure. It was found that the fermented fertilizer could grow faster compared to the control group.

\section{System Design}

\subsection{Design of Intelligent Solar Chicken Manure Fermentation System}

The system mainly includes the fermentation tank hardware structure and control system, wherein the fermentation tank hardware structure is divided into two parts: a fermenter and a temperature control. The fermenter section is horizontally matched with a water tank and a stirring blade, and the manure and decomposing bacteria are placed therein for fermentation. The temperature control part is divided into a solar heating and a backup gas-fuel water heater to make the fermenter reach a constant temperature. The temperature control system mainly uses the pumping motor to drive the solar hot water into an out-fringe of the fermenter tank to control the temperature. When the temperature of the fermenter tank is insufficient, the heating cycle is initiated. When there is no sun, the pumping motor is combined with the gas-fuel water heater as an alternate heating cycle. The control system first works as the main system architecture, and the secondary system is added to assist the main system to make the system more complete. The Protel 99SE circuit drawing software is applied for circuit planning and design for the circuit board. The main architecture of the control system is divided into circuit configuration and program design, and the system control core is Arduino MEGA 2560 as shown in Figure 1. The system control is divided into a stirring system, a temperature control system, and a drying system. A sketch diagram for the intelligent solar chicken manure fermentation system is shown in Figure 2. 


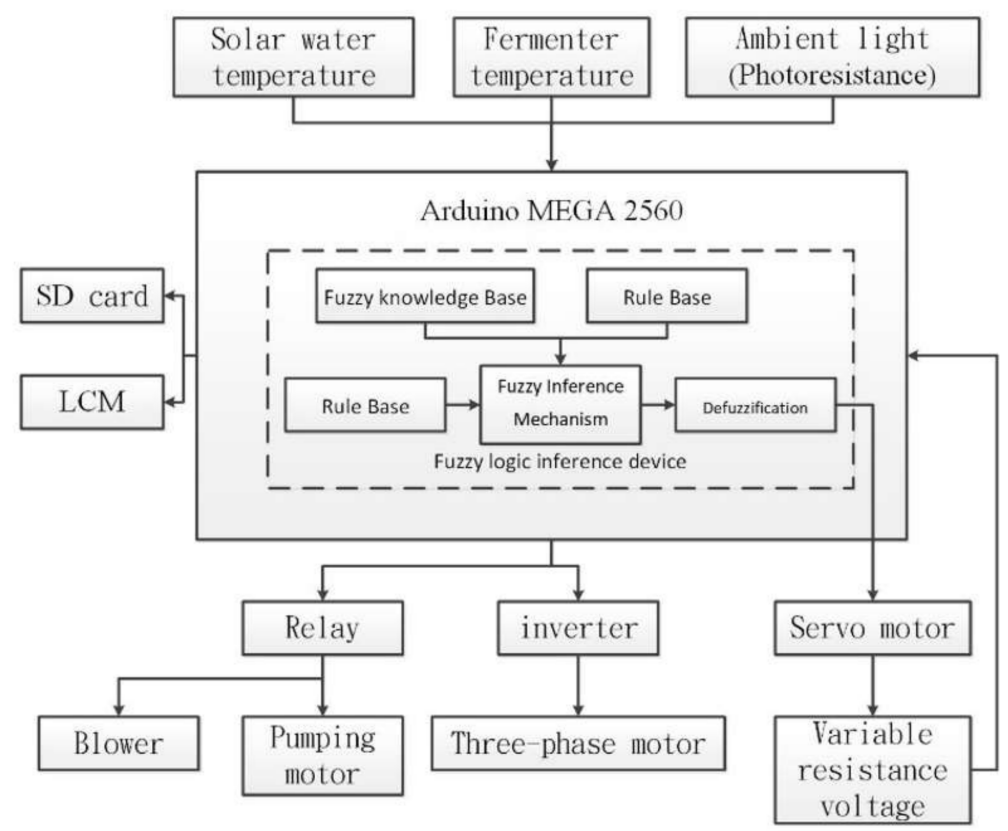

Figure 1. Master architecture diagram in control system.

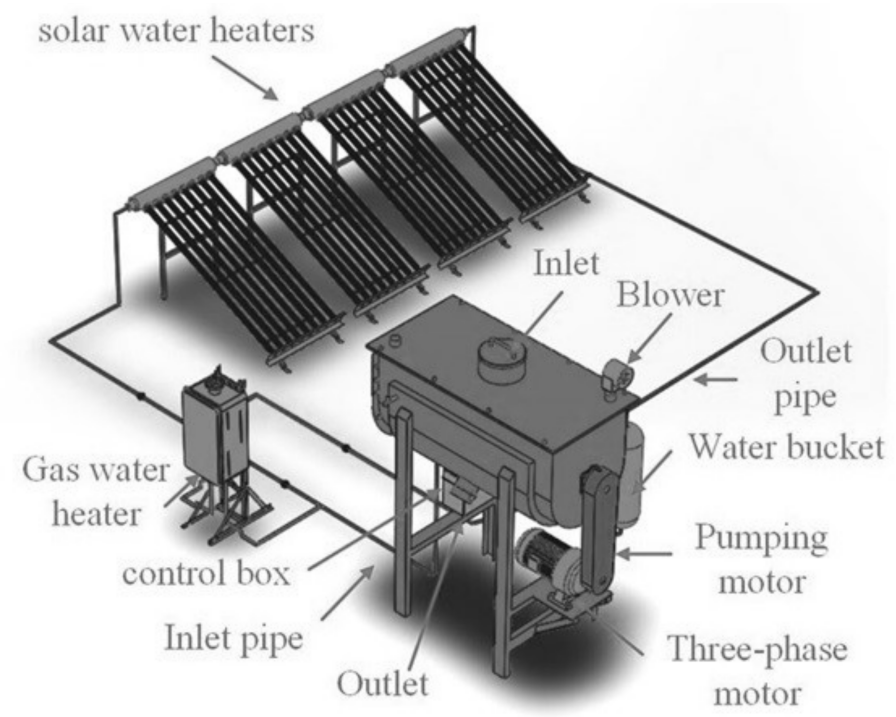

Figure 2. Outfit of intelligent solar chicken manure fermentation system.

\subsection{Structure Design and Construction of Fermentation Tank}

In this study the fermentation tank system was built on the outdoor ground, and a shelter was installed to avoid serious disturbance or rainwater accumulation. The structure of the fermentation tank includes blowers, pumping motors, and three-phase motors (Figure 3). The raw materials are placed from the above inlet port; fermentation starts with motor pumping, stirring, and blowing, and afterward finishes from the outlet leakage. Fermentation barrel body is a semi-circular body, the outer layer is made by the solar water heater with a hot-cold water exchange cycle to pour adequate water from the storage bucket, avoiding idle motor pumping. During fermenting mixing blades are driven by the three-phase motor and stirring blades are divided into outer and inner rings; when the blades turn clockwise, the raw material in the outer ring is driven from the outside, and the mixture of the inner ring is driven from the inside, as shown in Figure 4. 


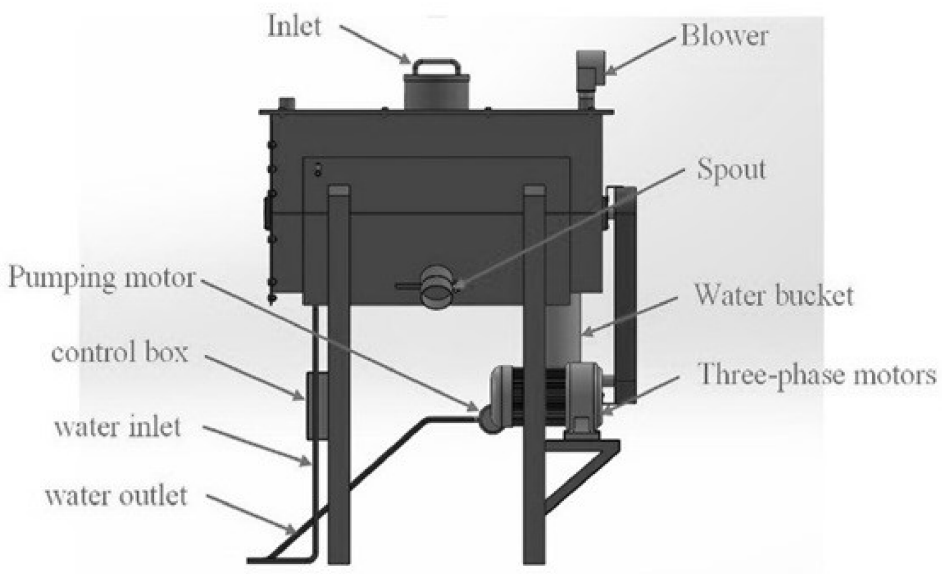

Figure 3. Fermentation barrel architecture diagram.

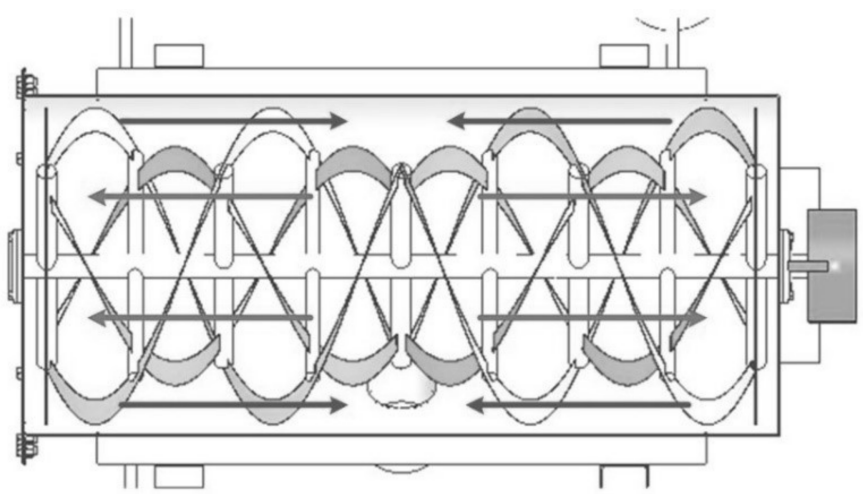

Figure 4. Stirring blade diagram in the fermentation tank.

\subsection{System Program Design}

The system is based on Arduino MEGA 2560 (Makerlab Electronics, Manila, Philippine) as the core of control for the solar fermentation barrel temperature control system process. The system output can be carried out manually or by setting the relevant parameters for the system to run automatically. This system sensor is installed inside the fermentation barrel, and the temperature is originally set to $40^{\circ} \mathrm{C}$. If it is less than $1^{\circ} \mathrm{C}$, pumping motor 1 will start immediately; if it is less than $5{ }^{\circ} \mathrm{C}$, pumping motor 2 will start immediately; if it reaches $40^{\circ} \mathrm{C}$ again, pumping motor 1 and pumping motor 2 will stop immediately. Arduino MEGA 2560 first initializes the SD card, and then probes the temperature inside and outside the fermentation barrel corresponding to inlet and outlet temperature of the solar water heater, and reads the current time from the RTC IC as the basis for data recording. Coupling with the LCM real-time display the data of the solar water heater temperature, the fermentation barrel temperature, humidity, and illumination are written to an SD card.

\subsection{Fuzzy Logic Intelligent Controller Design}

The Mamdani's Min-Min-Max fuzzy inference method is applied in this study as the fuzzy logic controller. In this study, Arduino MEGA 2560 is installed as a fuzzy logic controller by writing fuzzy set, rules, and attribution with $C$ language program expressions. The program converts to excite eight rules and PWM attribution values in line. The design fuzzy logic controller is executed by the following steps: (1) fuzzy logic architecture, (2) defines the fuzzy set of inputs, (3) defines the triangle attribution function, (4) defines the output attribution, (5) establish fuzzing rules, (6) fuzzy inference, (7) defuzzify. There are three parameter values for fuzzy logic input parameters: solar water heater temperature, 
fermentation barrel temperature, and ambient light. The number of PWM pulse waves is the output variable in the system.

The database to establish the fuzzy rule of this study adopts if-then rules; through the fuzzy logic intelligent control for the system, the fermentation barrel temperature is maintained at about $40{ }^{\circ} \mathrm{C}$. Additionally, the fermentation tank adopts a water bath to control the fermentation barrel temperature. The system mainly controls two sources of water with the solar water temperature at about $50-70{ }^{\circ} \mathrm{C}$ and groundwater temperature at about $20-26{ }^{\circ} \mathrm{C}$, and a fuzzy logic controller is used to control the valve by a PWM pulse signal to determine the amount of cold and hot water in and out to reach the proper mixing temperature in the control tank before entering the fermentation tank. While the temperature of solar hot water is lower in winter, gas heating will be operated to maintain $40^{\circ} \mathrm{C}$ in the fermentation tank. The system will activate the rule database with the sensor detecting the temperature, and then drive the valve to achieve the purpose of fuzzy logic temperature control with default inference.

\section{Experimental Design}

The measurement of this experiment is the temperature of the solar water heater, the temperature and humidity of the fermentation tank, the illumination, and the control angle of the servo motor, which are taken once every minute by manual sampling on the $\mathrm{pH}$ value, humidity, color, and particle size detects.

\subsection{Experimental Design of Measurement Location}

In this study, the input fuzzy control mechanism is applied, and the DS18B20 temperature sensor is installed on the solar water heater, which is used as the basis for controlling the solar pumping motor and the backup heater. To observe the temperature change of the solar water heater, we take the sensor temperature in a total of two points where DS18B20 temperature sensor set for the solar water heater in and out of the water port temperature as shown by Figure 5. In this system DHT11 temperature and humidity sensor and DS18B20 temperature sensor are applied, wherein the DHT11 temperature and humidity sensor measures the temperature and humidity in the fermentation barrel as well as in the environment as the basis for the blower, and the DS18B20 temperature sensor detects the outside temperature of the fermentation barrel and the temperature inside the fermentation barrel as shown by Figure 6. Data will input fuzzy controller for analysis. The temperature of the solar water heater is related to the PGM5506 photoresistor experiment, recording the voltage of the photoresistance every day, then input into the fuzzy controller for analysis, and the sensor is placed next to the solar water heater as shown in Figure 7.

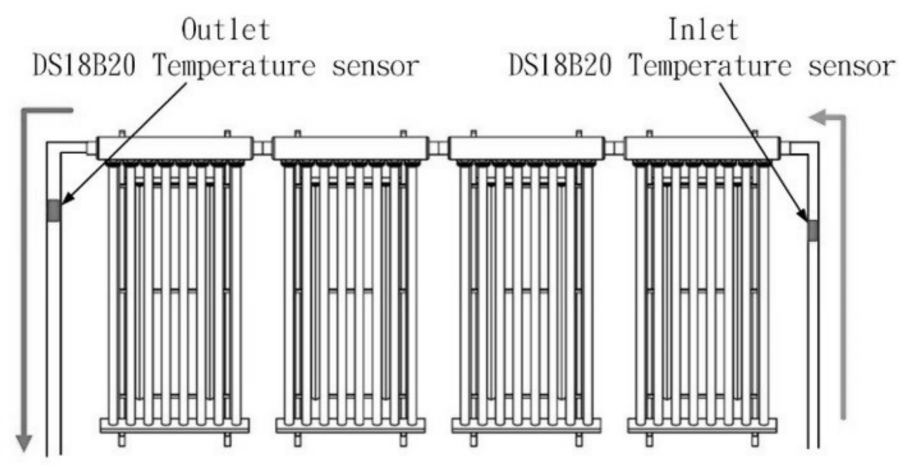

Figure 5. Temperature sensor placement in and out of the water port of solar water heater diagram. 


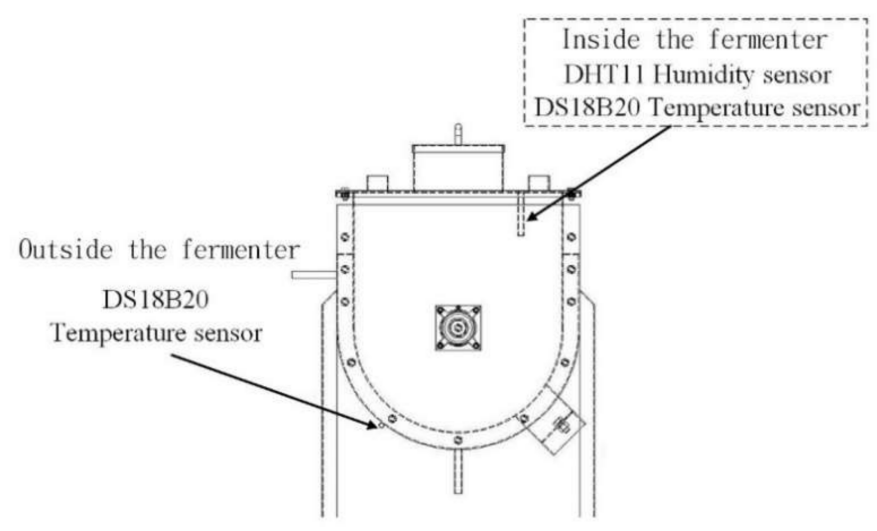

Figure 6. Fermentation barrel temperature sensor placement diagram.

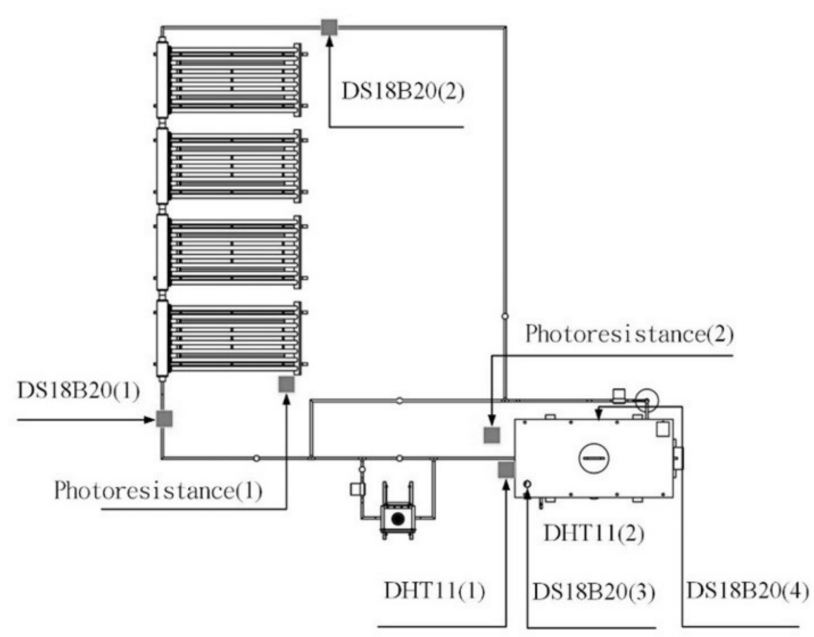

Figure 7. Photoresistor placement diagram.

\subsection{Method and Steps of the System Connection Test}

This experiment will test the temperature and humidity in the fermenter as well as in the air under different conditions and analyze the ambient temperature and humidity and the temperature and humidity of the fermenter. The experimental data are taken every minute.

(1) Uncontrolled solar water heater cycle: directly enter the fermenter tank from the hot water of the solar water heater.

(2) Control solar water heater cycle: when the temperature of the fermenter tank is greater than $40^{\circ} \mathrm{C}$, the pumping motor is stopped, and starts again while temperature is less than $40^{\circ} \mathrm{C}$.

(3) Control the circulation and internal circulation of solar water heaters: when the temperature of the fermentation tank is greater than $40{ }^{\circ} \mathrm{C}$, the solar energy is turned off to start the internal circulation, and when the temperature is less than $40^{\circ} \mathrm{C}$, the solar water heater enters the fermentation tank.

Another experiment for backup gas water heater for controlling the temperature is tested. In this experiment, when the temperature of the solar hot water is insufficient, the gas water heater will be operated, and the hot water will enter the fermentation tank for circulation. When the temperature of fermentation tank is slowly raised by fuzzy logic inference to control the servo motor, the servo motor can adjust the amount of gas. Two kinds of condition control methods are used, and the experimental data are extracted every minute. 
The experimental conditions and methods are tested in two parts, once every minute, and tested for $2 \mathrm{~h}$. Start fuzzy control gas water heater cycle. The amount of gas is controlled by fuzzy inference, so that the temperature of the fermentation barrel can always reach $40{ }^{\circ} \mathrm{C}$.

\subsection{Mixed Fermentation Experiment of Cultured Bacteria and Chicken Manure}

The inoculation step is listed: firstly, the clip is used as a sterilization tool. The clip is wiped with alcohol, and then the alcohol lamp is used for over-fire sterilization. When the device is cooled, it is then inoculated. More action must be performed to avoid infection by other bacteria. When the culture dish is opened, the clip should not touch the outer casing when it enters. Cut a $1 \mathrm{~cm}$-sized cube into the liquid bottle and seal it with aluminum foil. These experiments are applied to traditional fermentation and solar fermentation. Both experiments have been conducted twice, in cases with and without adding bacteria into chicken manure. The example of the solar fermentation flow chart is shown as Figure 8 to detect $\mathrm{pH}$ and dryness. The test was carried out every $8 \mathrm{~h}$, and the seed germination rate was analyzed after composting. The method was that $5 \mathrm{~g}$ of composted chicken manure after solar fermentation was mixed with $100 \mathrm{~mL}$ of $60^{\circ} \mathrm{C}$ warm water, and after $3 \mathrm{~h}$, it was filtered with fine gauze. Pipette $10 \mathrm{~mL}$ of the filtrate into the tissue paper in the Petri dish, and place 25 seeds of cabbage on the paper. The Petri dish is placed in a $25^{\circ} \mathrm{C}$ incubator. After 3 days, the seed germination rate and root growth are observed and recorded.

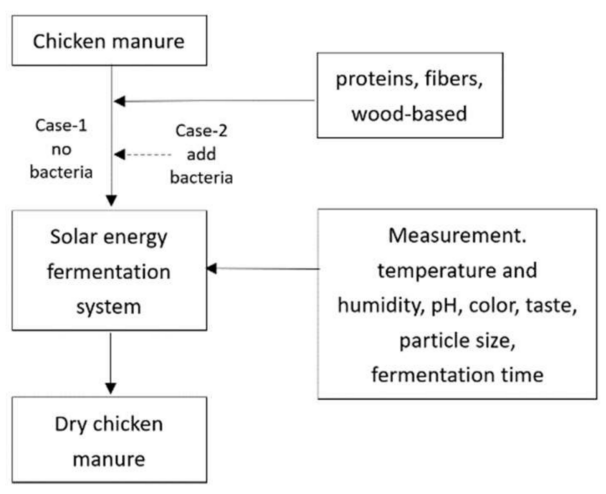

Figure 8. Flow chart of solar fermentation system.

An experiment of fermented fertilizer growth rate was conducted with a royal dish (falling sunflower, name: Basellaceae), which requires a stent to serve as a benchmark for measurement, while the royal cuisine begins to grow at a height of about $80 \mathrm{~mm}$, and then fertilizes it with a bacteria-fed chicken manure, sterile chicken manure, and control group, and observes plant growth every day for a duration of 16 days.

\section{Results and Discussion}

\subsection{System Online Test Results}

The entity of the system is shown in Figure 9. This experiment is divided into three types: the first uncontrolled solar water heater cycle from 27 to $51^{\circ} \mathrm{C}$, the second controlled solar water heater cycle from 25 to $42{ }^{\circ} \mathrm{C}$, and the third controlled solar water heater cycle from 25 to $41^{\circ} \mathrm{C}$, as shown in Figure 10. It is learned that the temperature of the first fermentation barrel is too high; the average temperature is about $48^{\circ} \mathrm{C}$. The temperature of the second kind of fermentation barrel is more than the temperature; the average temperature is about $41^{\circ} \mathrm{C}$. The temperature of the third fermentation barrel is too fast, the average temperature is about $38^{\circ} \mathrm{C}$. 


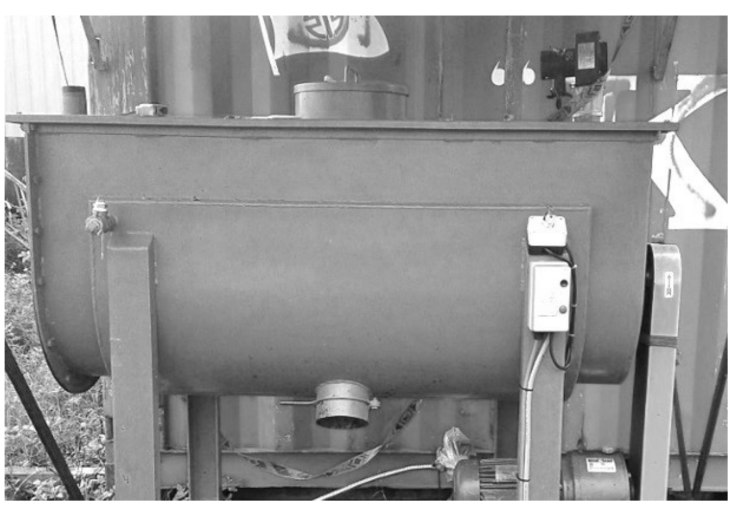

Figure 9. Prototype picture of system.

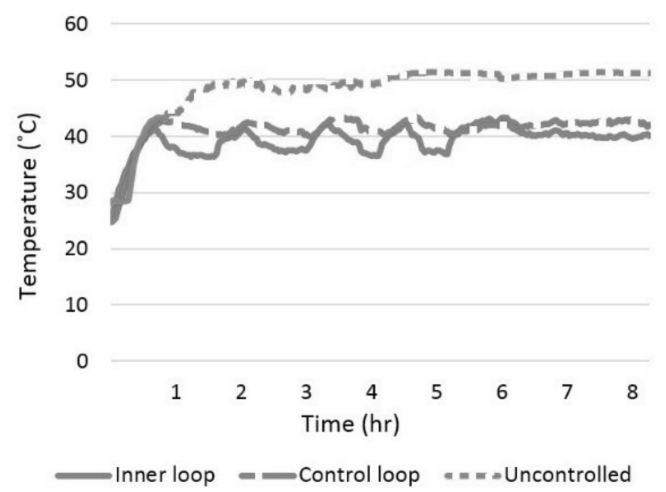

Figure 10. Test results with three types of temperature.

\subsection{The Results of Backup Gas Water Heater Experiment}

This experiment is divided into two kinds. The first one is to start the backup gas water heater cycle from 30 to $46^{\circ} \mathrm{C}$, and the second one is to start the fuzzy control backup gas water heater cycle from 28 to $41^{\circ} \mathrm{C}$. It is learned by the experiment that the use of fuzzy control system is relatively stable, as shown in Figure 11.

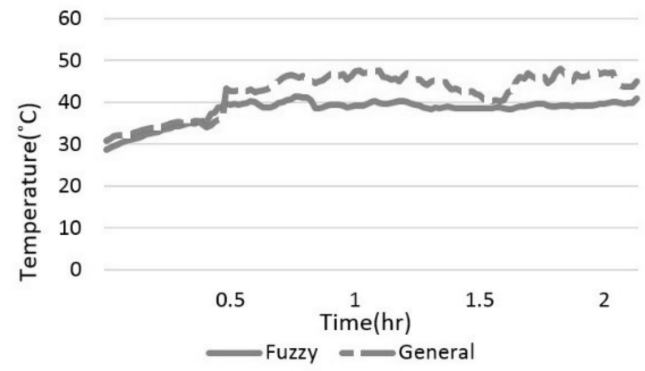

Figure 11. Comparison of the stable differences with or without fuzzy logic control.

\subsection{Fuzzy Logic Temperature Control Test Results}

Fuzzy inference experiment operation includes solar water heater temperature. The fermentation barrel temperature with the solar water heater temperature has the highest temperature from 11am to $6 \mathrm{pm}$; however, the night temperature is only $30^{\circ} \mathrm{C}$. Through the fuzzy logic intelligent control, the fermentation barrel temperature is maintained at about $40{ }^{\circ} \mathrm{C}$. In this study, Min-Min-Max is used to make fuzzy inferences, to blur the weight-based average method, and to verify the conformity with the continuous center of gravity method. 


\subsection{Chicken Manure Fermentation Test Results}

In order to understand the variation in $\mathrm{pH}$, comparison of sterile and added bacteria cases was applied to the traditional chicken manure fermentation, while the added bacteria case fermented faster, from pH8.6 to 10.2, as shown in Figure 12a. Comparison of sterile and added bacteria cases was applied to the solar chicken manure fermentation, while the fermentation of the added bacteria was also faster, from $\mathrm{pH} 8.7$ to 7.4, as shown in Figure 12b. The bacteria can quickly consume the nitrogen source of chicken manure and conduct acidification reaction. The taste of no bacteria is still very heavy, indicating that the fermentation has not been completed; nevertheless, the taste of added bacteria is relatively light, just like soil. Moisture content actually influences substance transformation during composting and the function of exogenous microbial agents [20]. The humidity in the fermentation barrel is extracted from the second to the third day, as the change is large, from $90 \%$ to $30 \%$, as shown in Figure 13. After around $50 \mathrm{~h}$ chicken manure forms small particles, as shown in Figure 14, it is assumed to reach a dry and powdery state.

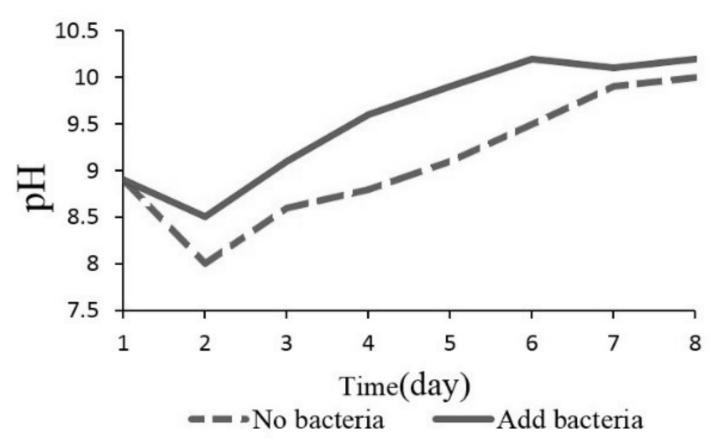

(a)

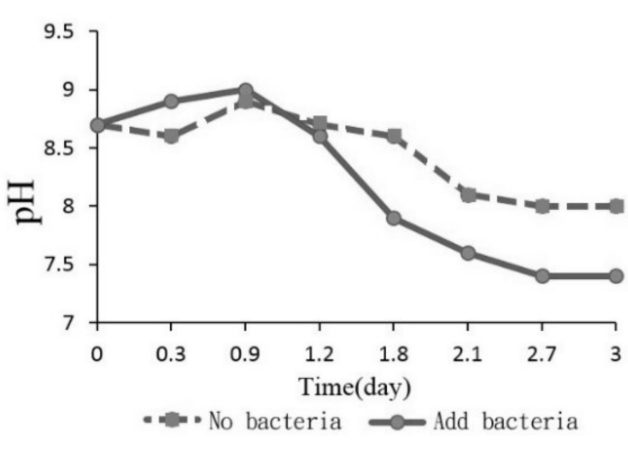

(b)

Figure 12. $\mathrm{pH}$ data diagram for (a) traditional fermentation and (b) solar fermentation.

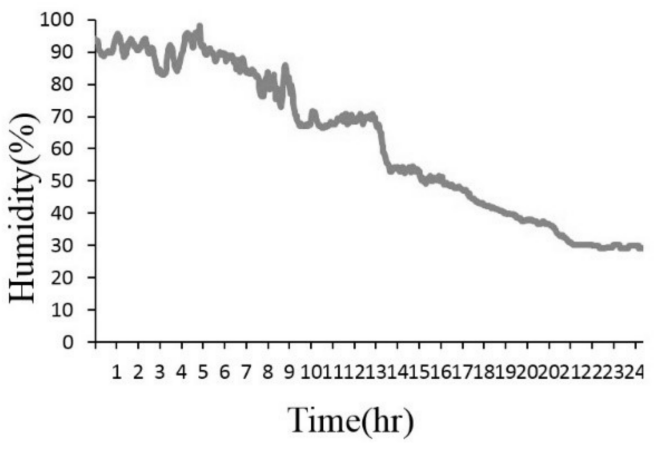

Figure 13. Humidity variation curve diagram.

\subsection{Results of Chicken Manure Fermentation and Planting}

After the chicken manure in system fermentation is completed, its germination efficiency is determined by culturing seeds. To observe its germination three days later, there are five germinations in the control group, no germinations in the no-bacteria group, and six germinations in the added bacteria group, which is a higher degree of germ ripening. Later on, the comparison of plant growth from 16 days of experiments is shown in Figure 15. The left side plant with $85 \mathrm{~mm}$ growth height applied fermented fertilizer of chicken manure with added bacteria. The middle plant with $60 \mathrm{~mm}$ growth height applied fermented fertilizer of chicken manure without bacteria. The right-side plant with $45 \mathrm{~mm}$ growth height applied fermented fertilizer of control group. It was found that the fermented fertilizer with the bacteria could grow faster. 


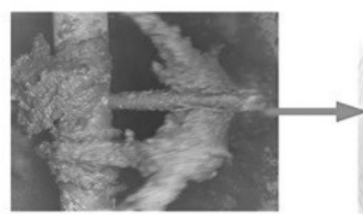

Start

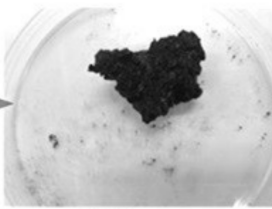

32 hour

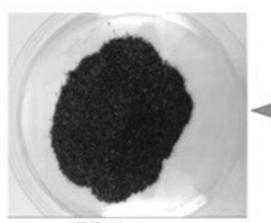

55 hour

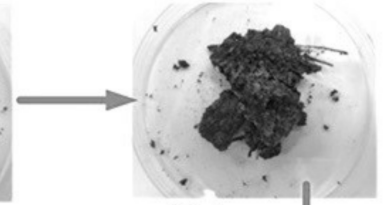

50 hour

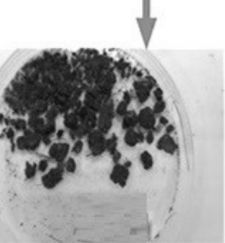

54 hour

Figure 14. Chicken manure treatment results from start to $55 \mathrm{~h}$.

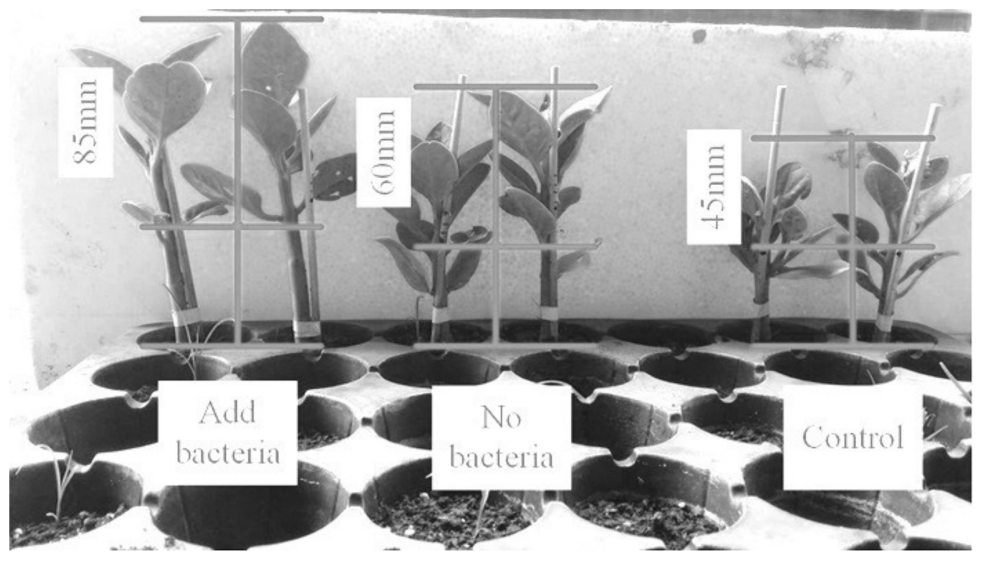

Figure 15. Differences in plant growth of fermented fertilizer results compared with control group, no bacteria group, and added bacteria group.

\section{Conclusions}

The fermentation barrel temperature could actually be stably maintained at about $40{ }^{\circ} \mathrm{C}$ through a proper fuzzy logic intelligent control. Then after, chicken manure formed small particles which were assumed to reach a dry and powdery state around $50 \mathrm{~h}$. Germination efficiency was determined by culturing seeds with fermented fertilizer of chicken manure. It was found that the fermented fertilizer could grow faster compared with the control group.

The fermentation system is available to rapidly dry and fermentation for the chicken manure, and the preliminary setup and experiment have been carried out. In future experiments, the researcher will analyze the decomposing bacteria and chicken manure deference. Moreover, the gas water heater is equipped with a sensor to ensure that the gas is leak-free, and the ignition system is safely started. Furthermore, when the amount of chicken manure is large, the agitating motor is liable to cause an overload, and it is necessary to replace it with a new one with large horsepower. The system combines a solar water heater to accelerate the temperature increase of the fermenter. However, the temperature of the fermenter and pipe is lost too quickly. Therefore, the current study will equip with an insulation system, such as adding insulation mats and thermal insulation barrels to increase the temperature maintenance for the fermentation tank to be closer to the application for industry.

Author Contributions: Conceptualization, J.-J.S.; methodology, H.-C.H.; hardware, H.-C.H. and M.-Y.S.; Formal analysis, J.-J.S. and Y.-C.C.; resources, data curation, M.-Y.S.; writing-original draft 
preparation, J.-J.S.; writing-review and editing, Y.-C.C. All authors have read and agreed to the published version of the manuscript.

Funding: This research received no external funding.

Institutional Review Board Statement: Not applicable.

Informed Consent Statement: Not applicable.

Data Availability Statement: The data presented in this study are available on request from the corresponding author. The data are not publicly available.

Conflicts of Interest: The authors declare no conflict of interest.

\section{References}

1. Lin, Y.F.; Shih, B.L.; Lin, M.C.; Liu, H.L. Research on the amount and contents of chicken excreta. Taiwan Livest. Res. 2009, 42, 291-298.

2. Hengchun Branch of Livestock Research Institute. Production and Utilization of Compost; Council of Agriculture: Taipei, Taiwan, 1995.

3. Cai, Y.; Chen, J. Development and Application of New Biological Fertilizers; Taichung District Agricultural Research and Extension Station, Council of Agriculture: Taichung, Taiwan, 1991.

4. Qiu, Q. Production and Use of Organic Fertilizer; Taoyuan District Agricultural Research and Extension Station, Council of Agriculture: Taoyuan, Taiwan, 1991.

5. De Bertoldi, M.; Vallint, G.; Pera, A.; Zucconi, F. Technological aspects of composting including modelling and microbiology. In Composting of Agricultural and Other Wastes; Gasser, J.K.R., Ed.; Elsevier Applied Science Publishers: London, UK; New York, NY, USA, 1985.

6. Zhou, M.; Shi, Z.; Chen, R.; Guo, M. Manual for The Production and Application of Livestock Manure Composting; Council of Agriculture: Taipei, Taiwan, 2009.

7. Xu, Z. Study on the Drying of Pig Manure Solids after the Separation of Solid Liquid by Solar Energy. Master's Thesis, National Chung Hsing University, Taichung, Taiwan, 2012.

8. Singh, Y.P.; Singh, C.P. Effect of different carbonaceous compound on the transformation of soil nutrients. I. Immobilization and mineralization of applied nitrogen. Biol. Agric. Horti. 1986, 4, 19-26. [CrossRef]

9. Chen, W. Equipment for the Rapid Conversion of Organic Fertilizers for Poultry Manure. Master's Thesis, National Kaohsiung First University of Science and Technology, Kaohsiung, Taiwan, 2012.

10. Li, J.M. Solar Heat Pipe Fermentation Equipment and Method. China Patent CN101899384A, 31 May 2009.

11. Li, J.N.; Wang, X.Y.; Zhang, Q.; Li, S. Automatic Fermentation Device for Treating Garden Waste by Utilizing Solar Energy. China Patent CN203653454U, 18 June 2014.

12. Boulal, A.; Kihal, M.; Khelifi, C.; Benali, B.J. Bioethanol production from date palm fruit waste fermentation using solar energy. Afr. J. Biotechnol. 2016, 15, 1621-1627.

13. Huang, H.C.; Lin, C.Y.; Shih, M.Y. A solar energy chicken faeces fermentation system with fuzzy logic control. In Proceedings of the 15th International Conference on Machine Learning and Cybernetics (ICMLC), Jeju Island, Korea, 10-13 July 2016; pp. 616-621.

14. Mondal, P.; Mondal, M. Temperature control inside a room using fuzzy logic method. Int. J. Innov. Res. Sci. Eng. Technol. 2018, 7, $7679-7685$.

15. Tarun, G.; Boudreaux, R.R.; Nelms, R.M.; Hung, J.Y. Implementation of a fuzzy controller for DC-DC converters using an inexpensive 8-b microcontroller. IEEE Trans. Ind. Electron. 1997, 44, 661-668.

16. Wong, L.K.; Leung, F.H.F.; Tam, P.K.S.; Chan, K.W. Design of an analog fuzzy logic controller for a PWM boost converter. In Proceedings of the IECON'97 23rd International Conference on Industrial Electronics, Control, and Instrumentation (Cat. No. 97CH36066), New Orleans, LA, USA, 14 November 1997; Volume 1, pp. 360-363.

17. Tzeng, C.B.; Young, M.S. A Preliminary Study of Fuzzy Control Parameters and Taguchi Method on DC servo motor control. In Proceedings of the International IEEE/IAS Conference on Industrial Automation and Control Emerging Technologies, Taipei, Taiwan, 22-27 May 1995; pp. 170-174.

18. Mudi, R.K.; Pal, N.R. A robust self-tuning scheme for PI- and PD-type fuzzy controllers. IEEE Trans. Fuzzy Syst. 1999, 7, 2-16. [CrossRef]

19. Saepullah, A.; Wahono, R.S. Comparative analysis of Mamdani, Sugeno and Tsukamoto method of fuzzy inference system for air conditioner energy saving. J. Intell. Syst. 2015, 1, 143-147.

20. Li, M.-X.; He, X.-S.; Tang, J.; Li, X.; Zhao, R.; Tao, Y.-Q.; Wang, C.; Qiu, Z.-P. Influence of moisture content on chicken manure stabilization during microbial agent-enhanced composting. Chemosphere 2021, 264 Pt 2, 128549. [CrossRef] [PubMed] 